studies suggest that the beliefs and values of people in lower socioeconomic groups, such as their tolerance and acceptance of the behavioural and social aspects of the disorder ${ }^{18}$ and their sense of low control or powerlessness, ${ }^{29}$ may help to explain the observed socioeconomic inequalities.

A "contact" study found that low social class at birth increased the duration of untreated psychosis. ${ }^{30}$ If, as we suspect, people with schizophrenia from lower social classes are not presenting to family doctors, those with the least financial resources and opportunities for employment may be the most exposed to the adverse effects of untreated psychosis. This delay may, at least partially, explain why people from lower social class have a less favourable outcome. ${ }^{13}$ Efforts to reduce the duration of untreated psychosis through earlier detection should be particularly focused on people in lower social classes. In addition, researchers should be careful to adjust for social class at birth if using age at first presentation as a measure of age at onset of schizophrenia.

We thank the St John of God Order and the Stanley Foundation for their support and staff of the General Register Office, Dublin, for help in locating birth registration records.

Contributors: EOC and FM initiated and designed the study in collaboration with MB and NT. FM, NT, and PF did the statistical analyses. FM and MB collected and validated the data. FM, EOC, NT, and CL wrote the first draft of the paper and all authors participated in the interpretation of the results and editing the paper. EOC is the guarantor.

Funding: Stanley Foundation and Hospitaller Order of St John of God.

Competing interests: None declared.

1 Goldberg EM, Morrison SL. Schizophrenia and social class. Br J Psychiatry 1963;109:785-809.

2 Wiersma D, Giel R, De Jong A, Slooff CJ. Social class and schizophrenia in a Dutch cohort. Psychol Med 1983;13:141-50.

3 Argyle M. The psychology of social class. London: Routledge, 1994.

4 Jones PB, Bebbington P, Foerster A, Lewis SW, Murray RM, Russell A, et al. Premorbid social underachievement in schizophrenia. Br J Psychiatry 1993;162:65-71.

5 Aro S, Aro H, Keskimäki I. Socioeconomic mobility among patients with schizophrenia or major affective disorder. A 17 -year retrospective followup. BrJ Psychiatry 1995;166:759-67.

6 Warner R, de Girolamo G. Schizophrenia. Geneva: World Health Organization, 1995 .

7 Croudace TJ, Kayne R, Jones PB, Harrison GL. Non-linear relationship between an index of social deprivation, psychiatric admission prevalence and the incidence of psychosis. Psychol Med 2000;30:177-85.
8 Murray RM, Lewis SW. Is schizophrenia a neurodevelopmental disorder? BMJ 1987;295:681-2.

9 Geddes JR, Lawrie SM. Obstetric complications and schizophrenia: a meta-analysis. Br J Psychiatry 1995;167:786-93.

10 Hultman CM, Sparén P, Takei N, Murray RM, Cnattingius S, Geddes J. Prenatal and perinatal risk factors for schizophrenia, affective psychosis, and reactive psychosis of early onset: case-control study. BMJ and reactive psyct

11 Sham PC, O'Callaghan E, Takei N. Schizophrenia following pre-natal exposure to influenza epidemics between 1939 and 1960. Br J Psychiatry 1992;160:461-6.

12 Susser ES, Lin SP. Schizophrenia after prenatal exposure to the Dutch hunger winter of 1944-1945. Arch Gen Psychiatry 1992;49:983-8.

13 Saugstad LF. Social class, marriage and fertility in schizophrenia. Schizophr Bull 1989;15:9-44.

14 Wynn SW, Wynn AH, Doyle W. The association of maternal social clas with maternal diet and the dimensions of babies in a population of London women. Nutr Health 1994;9:303-15.

15 Saxena S, Majeed A, Jones M. Socioeconomic differences in childhood consultation rates in general practice in England and Wales: prospective cohort study $B M J$ 1999:318:642-6

16 Turner RJ, Wagenfeld MO. Occupational mobility and schizophrenia: an assessment of social causation and social selection hypothesis. Am Sociol Rev 1967;32:104-13.

17 Hare EH, Price JS, Slater E. Parental social class in psychiatric patients. $B r$ J Psychiatry 1972;121:515-24.

18 Loebel AD, Lieberman JA, Alvir JMJ, Mayerhoff DI, Geisler SH, Szymanski SR. Duration of psychosis and outcome in first-episode schizophrenia. Am J Psychiatry 1992;149:1183-8.

19 Carbone S, Harrigan S, McGorry PD. Duration of untreated psychosi and 12 month outcome in first episode psychosis: the impact of treatment approach. Acta Psychiatr Scand 1999;100:96-104.

20 Department of Health and Social Security. Inequalities in health: report of a research working group. London: DHSS, 1980.

21 Central Statistics Office. Census of Population 1986 Classification of Occupa tions. Dublin: Stationery Office, 1986.

22 Birtchnell J. Social class, parental social class and social mobility in psychiatric patients and general population controls. Psychol Med 1971;1:209-21.

23 Schwartz JE, Fennig S, Tanenberg-Karant M, Carlson G, Craig T, Galambos N, et al. Congruence of diagnoses 2 years after a first-admission diagnosis of psychosis. Arch Gen Psychiatry 2000;57:593-600.

24 Mäkikyrö T, Isohanni $\mathrm{M}$, Moring J. Is a child's risk of early onset schizophrenia increased in the highest social class? Schizophr Re 1997;23:245-52.

25 Dohrenwend BP, Levav I, Shrout PE, Schwartz S, Naveh G, Link BG, et al. Socioeconomic status and psychiatric disorders: the causation-selection issue. Science 1992;255:946-52.

26 Cooper B. Social class and prognosis in schizophrenia. Br J Prev Soc Med 1961;15:17-41.

27 Roberts K. School, parents and social class. In: Craft M, Raynor J, Cohen $\mathrm{L}$, eds. Linking home and school. A new review. 3rd ed. London: Harper and Row, 1980.

28 Horwitz AV. Help-seeking processes and mental health services. New Dir Ment Health Serv 1987;36:33-45.

29 Bosma H, Schrijvers C, Mackenbach JP. Socioeconomic inequalities in mortality and importance of perceived control: cohort study. BMJ 1999,319:1469-70.

30 Clarke M, Brown S, McTigue O, Gervin M, Murphy P, Waddington JL, et al. Duration of untreated psychosis in first episode schizophrenia and its relationship to premorbid functioning. Schizophr Res 1999;36:38-9.

(Accepted 13 September 2001)

\title{
The impact of new drugs on management of glaucoma in Scotland: observational study
}

\author{
D N Bateman, R Clark, A Azuara-Blanco, M Bain, J Forrest
}

Glaucoma is one of the most common causes of blindness worldwide (it is exceeded only by cataracts), and it accounts for $12 \%$ of cases of registered blindness in the United Kingdom. ${ }^{1}$ The vast majority of patients with glaucoma do not become functionally blind, but the pronounced visual loss these patients have, and its effects on function, are not considered by current statistics. Most cases are due to primary opening angle glaucoma, the prevalence of which increases in elderly people and is well established. ${ }^{2}$

There are two main treatment approaches for glaucoma-medical and surgical. Trabeculectomy is the standard surgical procedure. Twenty years ago, topical $\beta$ blockers revolutionised the medical management of glaucoma, but in the early 1990s researchers advocated early operative intervention for glaucoma." Over the past five years, three new classes of drugs for this condition have been introduced-prostaglandin analogues (latanoprost), topical carbonic anhydrase inhibitors (such as dorzolamide), and $\alpha-2$ agonists (brimonidine). Patients with glaucoma are managed almost exclusively by ophthalmic services. ${ }^{4}$ We examined the impact of new treatments for glaucoma by examining prescribing and operating statistics for
National Poisons Information Service (Edinburgh), Scottish Poisons Information Bureau, Royal Infirmary of Edinburgh, Edinburgh EH3 9YW D N Bateman director

continued over

BMJ 2001;323:1401-2 
Information and Statistics Division of the Common

Services Agency of

NHS, Scotland,

Edinburgh

EH5 3SQ

R Clark

principal pharmacist

M Bain

consultant in public

health medicine

$\mathrm{J}$ Forrest

senior information

manager

Department of

Ophthalmology,

Aberdeen Royal

Infirmary, Aberdeen

AB25 2ZN

A Azuara-Blanco

consultant ophthalmic

surgeon

Correspondence to:

D N Bateman

nick.bateman@luht.

scot.nhs.uk

Trends in glaucoma care in Scotland

\begin{tabular}{|c|c|c|c|c|c|c|}
\hline Aspect of glaucoma care & 1994 & 1995 & 1996 & 1997 & 1998 & 1999 \\
\hline \multicolumn{7}{|l|}{ Surgery } \\
\hline Trabeculectomy (total operations) & 1714 & 1666 & 1504 & 1416 & 1265 & 951 \\
\hline $\begin{array}{l}\text { Trabeculectomy (per } 1000 \text { population estimated to have } \\
\text { glaucoma) }\end{array}$ & 46.0 & 44.4 & 39.9 & 37.4 & 33.2 & 24.8 \\
\hline \multicolumn{7}{|c|}{ Prescribing rates (items per 1000 population estimated to have glaucoma) } \\
\hline Miotics & 1411 & 1416 & 1322 & 1110 & 903 & 739 \\
\hline Other sympathomimetics & 1073 & 1068 & 947 & 724 & 520 & 366 \\
\hline$\beta$ blockers & 5182 & 5329 & 5505 & 5548 & 5592 & 5513 \\
\hline Oral carbonic anhydrase inhibitors & 285 & 259 & 248 & 223 & 215 & 203 \\
\hline \multicolumn{7}{|l|}{ New drugs: } \\
\hline Brimonidine & NM & NM & NM & NM & NM & 554 \\
\hline Topical carbonic anhydrase inhibitors & NM & 42 & 486 & 1080 & 1353 & 1496 \\
\hline Prostaglandin analogues & NM & NM & NM & 125 & 496 & 1059 \\
\hline Total items & 7952 & 8114 & 8508 & 8886 & 9444 & 9930 \\
\hline $\begin{array}{l}\text { Cost (£000s per } 1000 \text { population estimated to have } \\
\text { glaucoma) }\end{array}$ & 58.01 & 59.22 & 65.31 & 74.94 & 79.67 & 93.70 \\
\hline
\end{tabular}

NM=not marketed. *Based on costs given in British National Formulary. 40th edition, September 2000.

Scotland (population 5.1 million), correcting for estimated age related prevalence. ${ }^{2}$

\section{Methods and results}

The Scottish Morbidity Record for acute hospital discharges (SMR01) ${ }^{5}$ was used to identify all episodes of trabeculectomy, including phaco-trabeculectomy (OPCS4 code C60.1) between 1989 and 1999. Data were also obtained on cataract operations and newer surgical procedures (argon laser trabeculoplasty and diode laser cyclophotocoagulation). Data derived from prescriptions from general practitioners in Scotland were analysed by categorising the data into the five classes of glaucoma treatment defined in the British National Formulary (section 11.6)-miotics, sympathomimetics, topical $\beta$ blockers, carbonic anhydrase inhibitors, and prostaglandins-by cost and volume for 1994 to 1999 (the period for which data were available). Three drugs introduced after 1994latanoprost, dorzolamide, and brimonidine-were analysed separately. The population likely to have glaucoma was estimated from census data, using a model based on published epidemiological data. ${ }^{2}$

The annual number of trabeculectomies increased from 1202 in 1989 to 1855 in 1993 and then fell to 951 in 1999. Over the same period, cataract operations increased by $98 \%$, from 10049 to 19981 per year. We excluded argon laser trabeculoplasty and laser cyclophotocoagulation operations because only 144 and 64, respectively, were performed and the number varied considerably from year to year.

The number of items prescribed per 1000 patients with glaucoma increased from 7952 to 9930 (24.9\%) between 1994 and 1999; this increase was higher than the general increase in prescribing $(17.8 \%)$. Prescribing of topical $\beta$ blockers increased by only $6.4 \%$. The large increase in prescribing of new products was at the expense of older drugs-for example, there was a $47.7 \%$ fall in prescriptions for miotics. These changes resulted in a $61.5 \%$ increase in the cost of topical glaucoma treatments-by 1999 new drugs accounted for more than half of all this expenditure. Operation rates fell by $45.9 \%$, from 46 per 1000 patients with glaucoma in 1994 to 24.8 per 1000 patients with glaucoma in 1999 (table)
Other indices of ophthalmic activity increased. The number of eye tests increased from a total of 614447 in 1995 to 657213 in $1999(6.5 \%)$ and from 46845 in 1995 to 57894 in $1999(23.6 \%)$ for patients with glaucoma or their relatives; the numbers of optometrists increased from 979 in 1995 to 1343 in 1999 (37.2\%); and the whole time equivalent of ophthalmic surgeons increased from 167 in 1995 to 182 in $1999(8.2 \%)$

\section{Comment}

Three new classes of drugs used to treat glaucoma had a dramatic effect on the pattern of prescribing and the rate of operations in Scotland. It is unclear whether the new topical treatments are as effective as each other and, more importantly, whether they prevent, or just delay, the need for surgery. Statistics on other aspects of ophthalmic health care did not support the theory that changes in the detection of cases accounted for the reduction in glaucoma surgery, since the numbers of eye tests, optometrists and surgeons all increased in the study period.

Contributors: DNB was responsible for the original concept and developed this in collaboration with $\mathrm{AB}$ and $\mathrm{MB}$. Analysis of the database was carried out by RC and JF, who also took part in the initial discussions on the study. The manuscript was drafted by DNB and modified following discussion with all other authors. $\mathrm{DNB}$ and $\mathrm{MB}$ are the guarantors of the study.

Funding: None

Competing interests: None declared.

Evans J, Rooney C, Ashwood F, Dattani N, Wormald RW. Blindness and partial sight in England and Wales: April 1990-March 1991. Health Trends $1996 \cdot 28 \cdot 5-12$

2 Quigley HA, Vitale S. Models of open-angle glaucoma prevalence and incidence in the United States. Invest Ophthalmol Vis Sci 1997;38:83-91.

3 Migdal C, Gregory W, Hitchings R. Long-term functional outcome after early surgery compared with laser and medicine in open-angle glaucoma. Ophthalmology 1994;101:1651-6.

4 Harrison RJ, Wild JM, Hobley AJ. Referral patterns to an ophthalmic outpatient clinic by general practitioners and ophthalmic opticians and the role of these professionals in screening for ocular disease. BMJ 1988;297:1162-7.

5 Harley K, Jones C. Quality of Scottish morbidity record (SMR) data. Health Bull (Edinb) 1996:54:410-7.

(Accepted 1 August 2001) 